\title{
1
}

\section{The Nature and Importance of Innovation}

\subsection{Introduction}

This chapter begins by defining what economists mean by innovation. Economists have focused on two main types: product and process. A product innovation is the act of bringing something new to the market place that improves the range and quality of products on offer: for example, the Apple iPod is an innovation compared with the Sony Walkman, which was an earlier portable device for playing music. A process innovation is a new way of making or delivering goods or services: for example, going to visit the doctor and recording that you have arrived for your appointment by touching a screen instead of talking to a receptionist. We shall highlight the basis of such innovations in the discovery and development of many types of new knowledge. We begin by outlining the whole supply chain of innovation: from its basis in such activities as scientific invention, mathematical theorems, computing algorithms, and information gathering activity through to the widespread diffusion of this new knowledge embodied in new products and processes within the economy.

Section 1.3 looks at the microeconomic effects of innovation. Using the standard microeconomic concepts of costs, demand, and consumer surplus, the outcome of both process and product innovation are analyzed. Even at this stage we encounter differences depending on the availability of intellectual property rights (IPRs) and the type of market structure of the relevant industry. Section 1.4 looks at the interactive nature of innovation, whereby sectors of the economy can act as both producers and users of innovations. Section 1.5 considers the important question of whether or not the private market can deliver the optimal amount of innovation. If there is market failure, there will be less innovation than the amount society would ideally want. Here we stress two aspects of the process of innovation that suggest possibilities for market failure. The first is that new knowledge-which is created during the innovation process-is what economists term a public good and such 
goods tend to be underprovided by the private market. The second is that innovation can create positive externalities in the form of spillover benefits to customers and other firms and these cannot be captured as revenue by innovating firms, again leading to underprovision of innovation. Section 1.6 introduces the ways in which public policies, such as subsidies to research and development or the award of IPRs, can, to some degree, restore the efficiency of private firms and markets in the supply of innovation. Finally, section 1.7 briefly introduces an important process whereby firms compete through innovation, which will be discussed in more detail in subsequent chapters.

\subsection{What Is Innovation?}

Innovation can be defined as the application of new ideas to the products, processes, or other aspects of the activities of a firm that lead to increased "value." This "value" is defined in a broad way to include higher value added for the firm and also benefits to consumers or other firms. Two important definitions are:

- Product innovation: the introduction of a new product, or a significant qualitative change in an existing product.

- Process innovation: the introduction of a new process for making or delivering goods and services.

Some authors have emphasized a third category of innovation, that of organizational change within the firm, but we see this as being naturally included within the second category, as a type of process innovation. ${ }^{1}$

Product innovations may be tangible manufactured goods, intangible services, or a combination of the two. Examples of recent tangible product innovations that have had a very significant impact on the way people live and work are personal computers, mobile phones, and microwave ovens. Intangible products that complement these types of physical equipment include the various pieces of computer software needed to control flows of information through these devices, leading to the delivery of information, the supply of communication services, or the arrival of a correctly heated dinner. Equally, process innovations, which are new

\footnotetext{
${ }^{1}$ Joseph Schumpeter not only listed these three categories, but also defined as innovation the opening of a new market, or the development of new sources of supply for raw materials (OECD 1997, p. 28). We prefer to allocate these to entrepreneurial activity rather than to innovation.
} 
ways of making and doing things, can arise from the use of new combinations of tangible and intangible inputs. A robotic machine to assemble cars can deliver welding services with even greater precision than a human welder, but is only as good as its computer control system.

Inherent in the above definitions of innovation is an element of novelty. The question then arises as to how much novelty is enough to identify any change as "innovation." A key issue here is to distinguish innovation, the bringing to market of a truly novel item, from imitation, the adoption of a new technique or design that is already in the market. A product or process can be new to the firm, new to the domestic market, or new to the world market. Clearly, the last of these, global novelty, is sufficient to qualify the product or process as an innovation. For those goods and services that are not internationally traded-whether due to the nature of the product, prohibitive transport costs, or restrictions on trade-the test of being "new to the domestic market" is sufficient to establish that there is an innovation within that economy. In our view, being "new to the firm" is an insufficient test for innovation, as the firm in question may simply be adopting a product design, or a production method, introduced by a competitor. In this book we call this the diffusion of innovation. ${ }^{2}$ We define an innovation as new to the firm and new to the relevant market. Whether this relevant market is local or global is dependent on the product or process in question and the degree to which it is traded in a competitive global or local environment. ${ }^{3}$

Another feature of our two definitions of innovation is that the product or process must be introduced into the market place so that consumers or other firms can benefit. This distinguishes an innovation from an invention or discovery. An invention or discovery enhances the stock of knowledge, but it does not instantaneously arrive in the market place as a full-fledged novel product or process. Innovation occurs at the point of bringing to the commercial market new products and processes arising from applications of both existing and new knowledge. Thus we can see that innovation occurs at the kernel of a complex process, preceded by inventions and succeeded by the widespread adoption of the new

\footnotetext{
2 The Oslo Manual (OECD 1997), which was the guide for undertaking survey work on innovation in the early phase of the Community Innovation Survey, had a baseline definition of innovation that includes "new to the firm," hence conceptually mixing up "diffusion" and "innovation" (although they do draw attention to this problem, see pp. 35-36). Hence, surveys of innovation by firms frequently enquire about products and processes that are new to the firm, but sometimes fail to identify which of these items are also new to the market. The U.K. government reports from the Community Innovation Survey have frequently quoted the larger measure as an indicator of British innovation.

${ }^{3}$ We will discuss in chapter 2 the fact that some IPRs, such as patents, which are geographically limited in coverage, have the effect of dividing up world markets into protected trade areas.
} 
genre of products by customers, or the adoption of best-practice processes in the majority of firms. We call this final stage diffusion, and it is clear that the benefits of innovation to the economy and its citizens are not fully realized until this has taken place.

\section{Defining Knowledge and Technology}

Already we have begun to make continual reference to knowledge and technology. What do economists mean by these terms? Economically relevant knowledge is the whole body of scientific evidence and human expertise that is, or could be, useful in the production and supply of commodities and in the invention and design of new products and processes. Knowledge can be codified, as in a chemical formula or computing algorithm, or it can be tacit, as when a person knows how to do something that is not written down, like mixing and serving a perfect cocktail. When knowledge is embodied in individuals it is often referred to as human capital, to distinguish this valuable asset from physical capital, such as machinery or buildings. For an individual, the acquisition of new skills and knowledge through education and training increases his/her human capital.

Technology encompasses the current set of production techniques used to design, make, package, and deliver goods and services in the economy. So technology is the application of selected parts of the knowledge stock to production activity. Within the firm, the technology used determines its productive capability when combined with other inputs. Inventions and discoveries add to the stock of knowledge that can be applied to production. Some types of innovations, termed process innovations above, add to the available stock of technology for production, while product innovations add to the choice of products facing final customers.

\section{The Stages of the Innovation Process}

The innovation process has a number of stages that can be distinguished, as shown in figure 1.1. ${ }^{4}$ At each stage of the process there are activities requiring inputs of knowledge, embodied in skilled personnel and specialized equipment, and investment of time in using these resources. Additionally, each stage, if successful, produces an output,

\footnotetext{
${ }^{4}$ In his book The Economics of Production and Innovation, Rosegger (1986) identified five stages in the process of technological change. This framework was largely directed to explaining the sources of manufacturing innovation. We have modified this picture to include a more modern view of knowledge production, including computing and services, but we acknowledge the inspiration of Rosegger for this diagram.
} 


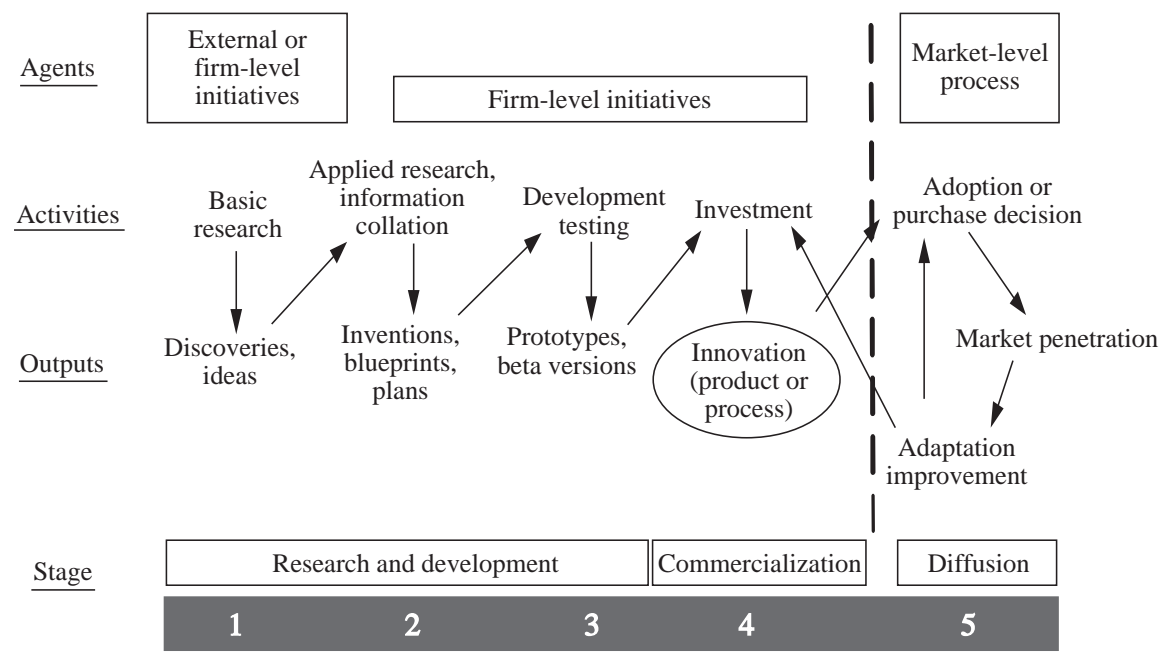

Figure 1.1. The stages of the innovation process.

initially intangible in the form of new knowledge but later tangible if applied to goods for sale-although sometimes remaining intangible if applied to some kinds of service activities.

The first stages (1-3) of the innovation process produce basic scientific knowledge, plans for new processes or blueprints, and initial prototypes of new products or processes. This is when we may talk of "inventions being made" and the hard work, or genius, of inventors. All of this activity is frequently lumped together as research and development (R\&D), but it represents premarket activity by a variety of agents, including public scientific institutions, universities, lone inventors, and firms. It is only when stage 4 is reached, at the point where there is a marketable product or new process, that innovation is achieved. This phase of commercialization triggers the start of another chain of events, broadly characterized as diffusion (stage 5), which covers the widespread adoption of the new product or process by the market. It is also vital to understand that there is feedback between the various stages: innovation is rarely a linear progression through the stages shown. There is also feedback between the diffusion and innovation stages. As consumers, or other firms, start using the innovations, they often adapt or improve them, or relay information on how to do so back to the innovating firms. ${ }^{5}$ This type of refinement, or incremental innovation, is often very important as the initial product or process is rarely perfect.

\footnotetext{
${ }^{5}$ This was discussed by von Hippel (2005) and earlier by Rosenberg (1982). We elaborate further on feedback effects later in this chapter.
} 
Incremental innovation can be contrasted with drastic innovation. The first makes a small change to an existing process or product. Drastic or radical innovation introduces a completely new type of production process with a wide range of applications and gives rise to a whole new genre of innovative products. ${ }^{6}$ Steam engines, the internal combustion engine, electricity, microprocessors, and the Internet can all be considered examples of drastic innovations. Their introduction dramatically changed the way the economy worked and a huge range of other innovations followed in their wake. Box 1.1 discusses the specific example of the laser, originally invented and patented in the late 1950s. The laser gave rise to a number of drastic product innovations, such as compact discs and laser printers, each of which then underwent a series of incremental innovations. In addition, the laser also led to a number of drastic process innovations, such as the use of lasers in welding and surveying.

For any single innovation, all of the stages 1-4 in this diagram are not always conducted in a single firm. In many sectors of the economy public research institutions and university departments will be contributors to the flow of new knowledge that can be translated by firms into innovations. We shall discuss this relationship between the so-called science base and private industry in chapter 4 . Even where the relevant new knowledge is produced commercially there can be a separation of activity across firms. In fields such as biotechnology and pharmaceuticals, specialist firms exist to perform the R\&D of stages 1 and 2, while other firms supply stage 3 testing services for potential new drugs. All of these activities can take place at arm's length from the final marketplace, under contract from the firms that will eventually bring successful new products to the market. This merely indicates that specialization and contracting-out can occur in any part of the innovation process, so long as suitable contracts can be written and enforced.

\section{Box 1.1. The laser.}

The laser provides an interesting case study in invention and innovation. Laser stands for "light amplification by stimulated emission of radiation." Some claim that the laser was invented in Bell Laboratories by Arthur L. Schawlow and Charles Hard Townes in 1957, although the science it was based on had been developed previously, and others were also working in the area. Bell Labs filed a patent application in 1958 and this was granted in 1960. A scientific paper by Schawlow and Townes was also published in 1959 describing the principle of making a laser. Gordon Gould at Columbia had also written down plans for a laser in

\footnotetext{
${ }^{6} \mathrm{~A}$ formal, theory-based definition of drastic process innovation is made in section 2.2.
} 
1957, although he did not file for a patent until 1959. Since the U.S. patent system then worked on "first to invent," not "first to file" as in most other countries, this led to a series of legal disputes over the next thirty years surrounding who owned the intellectual property.

The scientific paper, and the initial patents, stimulated a race to build working lasers and improve their performance. Patents were, in turn, filed on many of the improvements. While the invention of the laser is an example of a radical invention, the huge numbers of subsequent improvements (called incremental innovations) in terms of wavelengths, power, size, and cost have dramatically influenced the laser's applicability. Over the last fifty years lasers have found applications in a wide range of scientific, industrial, and consumer applications. Industrial applications include surveying, weaponry, and medicine. They are also the basic technology that allows bar code scanners, compact discs, and laser printers to work. Lasers are also central to the use of fiber optic cables to carry huge volumes of data across the Internet and between computers.

\subsection{The Microeconomic Effects of Innovation}

We have already seen that there are two main types of innovation: process innovation, the introduction of new techniques for production, and product innovation, the offer for sale of a new type or design of a good or service product. Of course, these two are not always independent: often it is the introduction of a new process that permits the design and development of a range of new products, while the introduction of a new intermediate product permits a purchasing firm to change its production process. For the moment though, let us consider the different nature of the two kinds of innovation to examine how they impact on prices and costs. Their impact will, in turn, depend on the "market structure" in which the firm operates. ${ }^{7}$ Market structure refers to the nature of competition between the firms in the market. The two polar cases are "perfect competition," where there are a larger number of firms, and monopoly, where one firm dominates the market.

\section{The Effects of Process Innovation}

The essential effect is one of cost reduction in production. In economics, total costs are divided into fixed and variable costs and, in turn, we can define average costs (ACs) and marginal costs (MCs). Figure 1.2 shows a simple case where, before the innovation, firms have costs $\mathrm{AC}_{1}$ and $\mathrm{MC}_{1}$,

\footnotetext{
${ }^{7}$ Innovation will also shape the market structure as the causality runs both ways.
} 


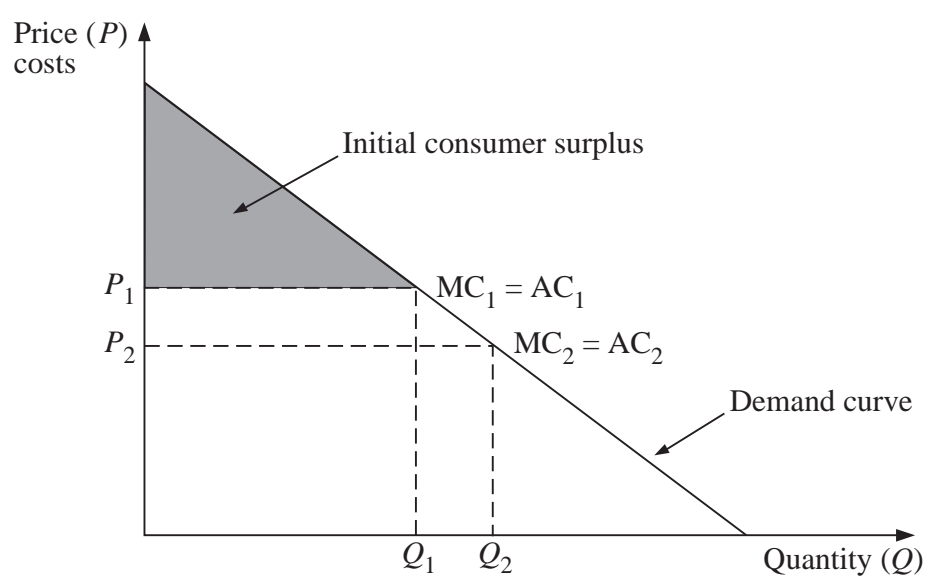

Figure 1.2. Process innovation in a perfectly competitive market.

which are equal (meaning there are no fixed costs). The demand curve for the industry is shown (and we will assume that this is unchanged in the case of a process innovation). If the industry is perfectly competitive, we assume that there are many firms, and each of these will set their price equal to $\mathrm{MC}_{1}$, hence the output produced and sold is $Q_{1}$ (at price $\left.P_{1}\right) .{ }^{8}$ Economists refer to the consumer surplus as a measure of benefit-it is the area between the demand curve and price-and this is the shaded area in figure 1.2. The process innovation is assumed to reduce the average or marginal cost of production. In our simple case, marginal and average costs are equal, so we can illustrate the impact of the process innovation by a fall to $\mathrm{AC}_{2}=\mathrm{MC}_{2}$. This also means that the price to consumers has fallen (to $P_{2}$ ) and the consumer surplus has risen (it is now the area above $P_{2}$ and below the demand curve). It is important to note that there are no IPRs in this example. If the market is perfectly competitive, all knowledge about production is assumed to be known by all firms. Hence, as soon as the process innovation occurs we assume that all firms immediately start to use it (the problems with this assumption are discussed in chapter 7). In such a case there is no financial incentive to undertake R\&D targeted toward creating the process innovation. Note that this occurs since prices are equal to marginal costs and average costs. This means that there are no economic profits to reward the innovator. ${ }^{9}$

\footnotetext{
${ }^{8}$ If a "perfectly competitive" market is unfamiliar, consult the mathematical appendix or a microeconomics textbook.

${ }^{9}$ Formally, the definition of average costs includes some return to the owners of capital and the managers of the firm; however, average costs do not include any additional return for innovation or entrepreneurship. The term economic profit signals when such returns are present.
} 


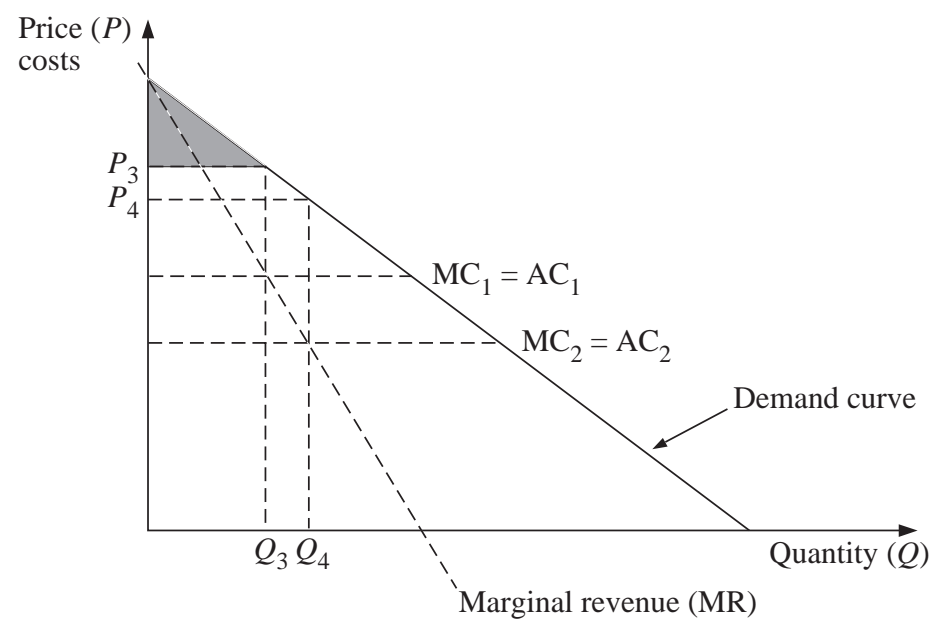

Figure 1.3. Process innovation for a monopoly.

The above case considered a perfectly competitive market with many firms selling an identical product. Given this situation, and the assumption of immediate knowledge diffusion, there is no financial incentive to develop a process innovation. Process innovations could occur if they originated by chance or were made by those unmotivated by financial incentives. Consider now a world where IPRs exist and where any process innovation could receive perfect protection. If one firm in the industry developed the process innovation discussed above, and secured a patent on it, it would be possible for that firm to undercut the price charged by any other firm. The innovator could produce and sell the good for a price $P_{1}-\varepsilon$ (where $\varepsilon$ is a small number). At this price it would sell almost $Q_{1}$, meaning that the profits it could make are approximately $\left(P_{1}-\varepsilon-\mathrm{AC}_{2}\right) \times Q_{1}$. Even if the innovator did not want to produce all of the market demand, in principle it could license its process innovation to all other firms and receive royalties equal to these profits. Introducing patents certainly increases the financial incentive to innovate.

Perfect competition is unlikely to occur in many industries so economists are interested in studying the other extreme form of market structure: monopoly. Assuming there is a permanent monopoly supplier with the demand and initial cost conditions specified above, would it have any incentive to make a process innovation? Figure 1.3 shows the same demand curve and initial costs as in figure 1.2 but in the case of a monopolist it will maximize profit by producing where marginal revenue (MR) is equal to $\mathrm{MC}_{1}$. This means the price is $P_{3}$ and the output produced and sold is $Q_{3}$-less than when there is perfect competition - and the profits are $\left(P_{3}-\mathrm{AC}_{1}\right) \times Q_{3}$. If the monopolist develops a process innovation, it 
lowers marginal cost to $\mathrm{MC}_{2}$. The new, lower marginal cost means that the monopolist will produce where $\mathrm{MR}=\mathrm{MC}_{2}$. This means a lower price $\left(P_{4}\right)$, more output $\left(Q_{4}\right)$, higher consumer surplus, and also higher profits for the monopolist. Thus, even with a monopolist, a process innovation will lower prices and benefit consumers. However, if the monopolist is not threatened with entry, there is no role for IPRs: the monopolist will receive additional profits since it is the only seller in the market. ${ }^{10}$ This finding assumes that monopolists will always seek to maximize profits by cutting costs and making innovations, an assumption that many economists think is too strong.

\section{The Effects of Product Innovation}

The successful development of a new product results in a different configuration of changes in costs and rewards. In a perfectly competitive market, and in the absence of IPRs over the new product (i.e., we assume that any product innovation can be immediately copied), there is no gain to the innovator. This case of immediate imitation by all other firms in the market is very unlikely. More realistically, the innovator uses some form of IPR or, failing this, relies on secrecy or first-mover advantages to delay imitation (the same would be true in the process innovation case discussed above). Given this, we can represent the introduction of the new product with a new demand curve. Figure 1.4 shows the demand curve for a new consumer good. The position and elasticity of the demand curve depends on how much the new product is valued, which in turn depends on the availability of substitute products. If we assume that the firm has an IPR that prevents imitators, the firm acts like a monopolist and maximizes profits. Hence, figure 1.4 is the same as figure 1.3 except that it represents a new product. Note that the new product creates "consumer surplus": the triangular area above the price but below the demand curve. This is a measure of the surplus value to the consumers over and above the price they have to pay. ${ }^{11}$

However, because price $\left(P_{1}\right)$ is greater than marginal cost $\left(\mathrm{MC}_{1}\right)$, consumer surplus is not maximized, since this would occur at $Q^{*}$. It is clear that rewarding innovations with profits (i.e., allowing $P$ to be greater than MC) creates a further problem. Looking at figure 1.4, we can see

\footnotetext{
${ }^{10}$ If the monopolist is threatened with entry, this will alter the incentives. Further cases are discussed in chapter 5 .

${ }^{11}$ More of the consumer surplus can be extracted by the firm if it can price discriminate. Equally, in some cases new products may be sold at low prices (i.e., less than $P_{1}$ shown) to achieve market share now with the view to increasing prices later. The possibility of such dynamic profit maximization is not considered by figures $1.1-1.3$, which view the market as static.
} 


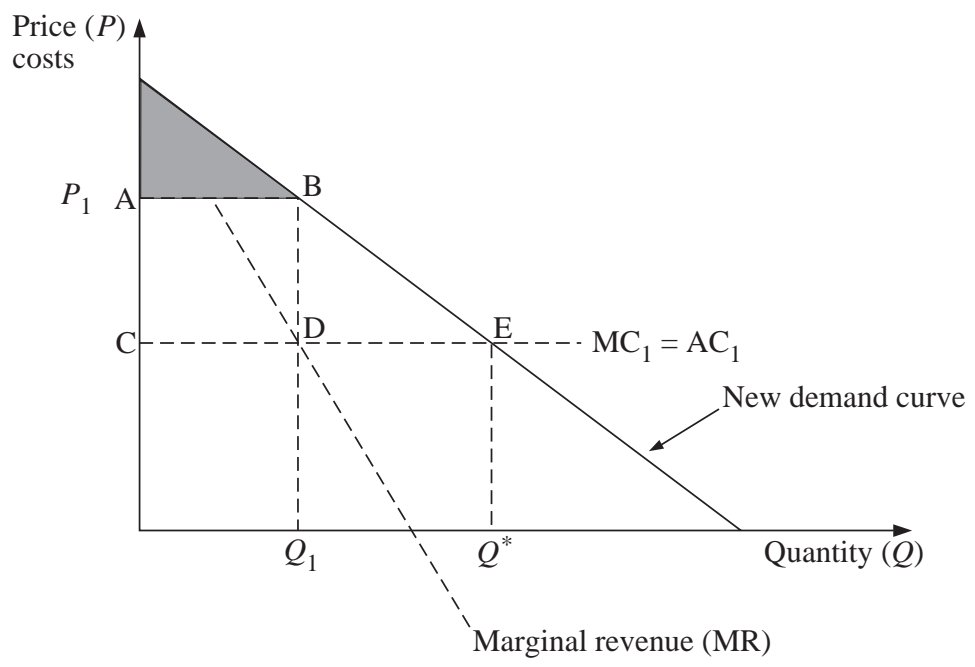

Figure 1.4. Product innovation for a monopoly.

that some of the lost consumer surplus is, in fact, profits to the innovator (i.e., area $\mathrm{ABCD}$ ), but some of the lost consumer surplus is wasted (i.e., area BDE). For this reason, area BDE is called the "deadweight loss" associated with monopoly pricing. Consider as an example the situation where an important new drug, that can treat a serious disease, is developed. During the period of protection by a patent, it is sold at a higher price than its marginal cost of production. Some sufferers who could afford the drug if priced at marginal cost are not able to obtain it at this higher price; the number of people affected is proportional to the distance $Q^{*}-Q_{1}$.

If the product innovation creates a new variety or improves the quality of an existing product, then drawing a new demand curve is not the best way to conceptualize the change. Suppose the market is imperfectly competitive before this product innovation, hence the firm already faces a downward-sloping demand curve. By introducing a new product the firm aims to achieve an outward shift and steeper slope to the demand for its product (analogous to the effect of advertising, increasing product loyalty to the firm). Figure 1.5 shows such a demand shift. Note that even though consumers are charged a higher price, they buy more and have more consumer surplus. Of course, over time the market may become more competitive as more product innovation occurs and this may reduce prices. A general way of describing this situation is to say that consumers benefit from the increase in product variety and/or the rise in the quality of the products on offer. Even if a new product is more expensive than existing ones, if it has exactly the right set of 


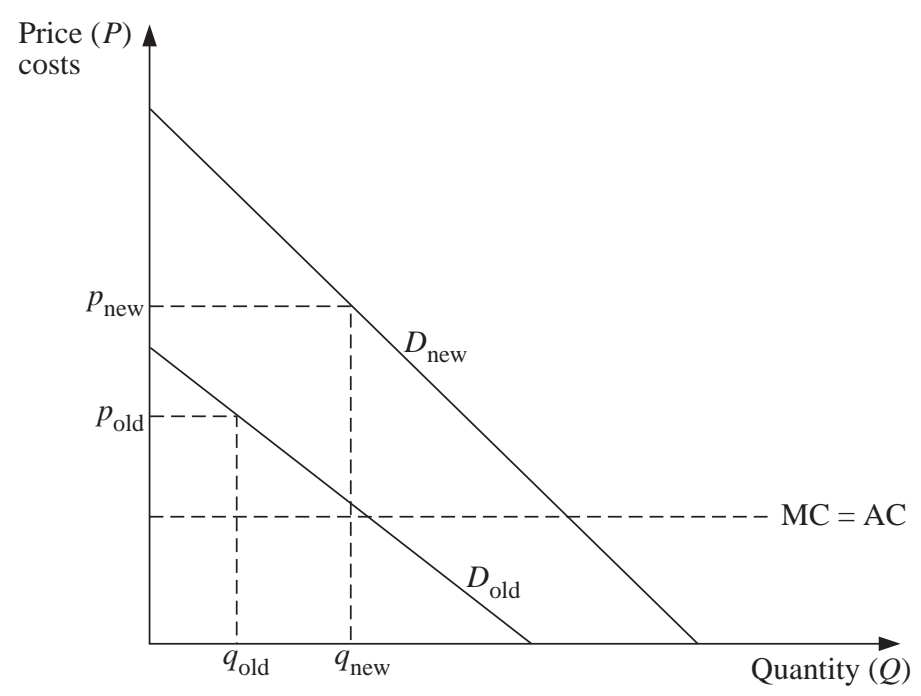

Figure 1.5. A product innovation represented by a shift in the existing demand curve.

characteristics to match the customers' tastes, they may be happier to buy this item. If the product has a broader and more favorable set of characteristics than an earlier variety, then, even with a higher price, it can still be seen as good value for money. (Further analysis of these alternative situations is given below in chapters 3 and 5.)

\section{Can Product and Process Innovations Be Distinguished?}

Conceptually yes, but in practical measurement terms it is often difficult to make this distinction. The basic reason is that in many cases of innovation, one firm's finished product can become part of another firm's production process. Innovation measurement at the level of the firm suggests that product innovations are in the majority (see Scherer 1984), while in the context of the economy they result in a large amount of process innovation. Some examples are new fertilizers that improve the productivity of agricultural production; new weaving machinery that enables the textile industry to create superior fabrics; cash dispensers that allow the banking industry to offer people access to their money at any time of day or night; and new computer software that permits firms in many sectors to organize information more efficiently.

A more detailed explanation of this issue is illustrated in box 1.2, where we outline a simplified Leontief input-output model of an economy. ${ }^{12}$ Although economic theory often analyzes supply as if there was

\footnotetext{
${ }^{12}$ For a fuller treatment of this type of model see Leontief (1986).
} 
a single-stage production process, transforming raw materials directly into final goods and services sold to consumers, this is an extreme simplification. In reality, much economic activity is devoted to the production of intermediate goods and services, which are supplied to other firms as semifinished products. In fact, the gross output of each sector (denoted by $X$ in box 1.2), reflecting economic activity before netting out the amount reabsorbed as inputs, is much bigger than its contribution to gross domestic product (GDP) (labeled $F$ in box 1.2). For example, total gross output was around 1.7 times GDP in the United Kingdom in recent data. Even from so-called final goods $F$, the share of GDP items purchased by firms for investment (I) also returns into production as capital inputs to the production process in the next period.

\section{Box 1.2. Leontief's input-output flow matrix.}

The Leontief input-output matrix is a way of visualizing how an economy is integrated. As an example we will consider a two-sector economy, consisting of manufacturing, sector $\mathrm{M}$, and services, sector $\mathrm{S}$.

In current-period production, each sector buys some of the other's products to use as inputs ( $A_{\mathrm{MS}}$ and $A_{\mathrm{SM}}$ ). Each sector also uses part of their own sector's output as inputs $\left(A_{\mathrm{MM}}\right.$ and $\left.A_{\mathrm{SS}}\right)$. Gross output $X$ (where total $X=X_{\mathrm{M}}+X_{\mathrm{S}}$ ) is therefore bigger than the net output for final demand $F$ (where total $F=F_{\mathrm{M}}+F_{\mathrm{S}}$ ) due to the absorption of part of gross output as intermediate goods.

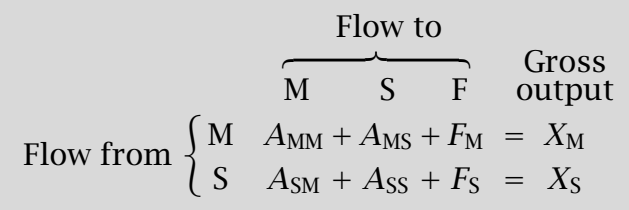

Further interrelationships occur in the next period arising from investment. Each sector's final demand $F$ is divided between consumption, $C$, and investment, $I$.

Thus

$$
\begin{aligned}
F_{\mathrm{M}} & =C_{\mathrm{M}}+I_{\mathrm{M}}, \\
F_{\mathrm{S}} & =C_{\mathrm{S}}+I_{\mathrm{S}},
\end{aligned}
$$

but investment in each sector also involves the purchase of some of the other sector's output ( $B_{\mathrm{MS}}, B_{\mathrm{SM}}$ ). Investment in each sector also involves use of part of own final output $\left(B_{\mathrm{MM}}, B_{\mathrm{SS}}\right)$. These investment flows again produce a mixing of sectoral outputs. 


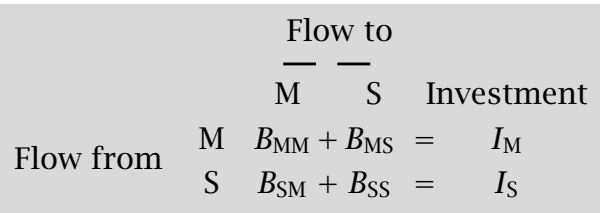

The row sum is the total investment of goods and services produced by each sector. The column sum (not shown) is the total investment of goods and services within each sector.

\section{Flows of Innovation Round the Economy}

Every process innovation within a sector causes lower costs of inputs supplied to user firms. Every product innovation within a sector causes new product varieties of inputs for user firms. These can lead to new processes of production in the user industry, due either to new intermediate products $\mathrm{A}$, to new investment products $\mathrm{B}$, or to cost changes that make different techniques more profitable.

\subsection{Interaction between Producers and Users of Innovation}

The description in figure 1.1 characterizes R\&D, innovation, and diffusion as a simple, sequential process, although you might have noticed one arrow drawn from right to left between stage 5 and stage 4 . As discussed above, firms can be involved in some or all of the distinct stages but the sequence of activities appears to flow strongly from left to right: from basic R\&D to subsequent commercial application in one innovating firm, and later spreading out via the diffusion process to many firms and customers. Not all authors see this linear model as an adequate depiction of the processes leading to innovation and diffusion. The Leontief input-output model (box 1.2) already raises the question of which sectors are supplying innovation to which other sectors, creating a relationship between the producers and the users of these innovations. ${ }^{13}$ Once these innovation supply relationships are established, there can be many instances where users of innovations feed back information about the product's performance, making suggestions for improvements and in this way helping to create the next generation of products they will buy. This alternative viewpoint requires the linear model employed above to be modified, to allow for interaction between innovators and their

${ }^{13}$ For an application of the Leontief model in tracing the production and use of innovations, see Scherer (1984, chapters 3 and 15). 
customers, including information feedbacks. Many companies encourage customer feedback, especially with respect to innovation. Proctor \& Gamble, one of the world's leading consumer product firms, spends hundreds of millions each year on monitoring and understanding customers' demands (including monitoring blogs and Web sites). In the software industry, the release of "beta versions" are specifically designed to allow users to provide feedback. For example, a beta version of Microsoft's Windows Vista was released in January 2005, after which various changes were made before Vista was released in February 2006.

Pavitt (1984) was among the early exponents of the idea that innovation is a complex interactive process, exhibiting considerable variability across sectors as to whether innovations were mainly produced inhouse by the firm or imported in the form of new equipment supplied by specialist producers. He created a taxonomy of sectoral patterns of technical change, examining each industry group to see what were the dominant patterns of production and use of process and product innovations. He initially identified four distinct groups of industries in terms of their technology acquisition and use: those that are supplier dominated, importing new elements of process technology but making little contribution via in-house R\&D; scale intensive producers, who contribute quite a lot of their own innovations and work these into profit through the operation of large-scale continuous production processes; specialized suppliers, whose main focus is the generation of product innovations in intermediate goods or capital equipment for use in other sectors; and science-based sectors, where firms engage intensively in in-house $R \& D$ based on advances in universities and public research institutions to produce both new products and new processes. His categorization was later refined and extended to include a group of service industries termed information intensive, which includes firms in finance, retail, and publishing (see Tidd et al. 2001). A further change since Pavitt's work in the 1980s has been the rise of information technology companies, so Greenhalgh and Rogers (2006) included a sixth category of software-related companies in their examination of sectoral differences in innovation using Pavitt's taxonomy.

\subsection{Innovations and Market Failure}

We have already seen that an innovation can benefit more people and companies than just the innovating firm. If the firm cannot charge all the beneficiaries of its innovation, then there is a problem of matching incentives to the value of the activity, which may lead to an undersupply 
of innovations. The possibility that the market system, guided by the independent actions of private firms, will not lead to the optimal outcome is called "market failure." Microeconomists are particularly interested in instances of market failure and we will consider four cases now. First, that the new knowledge underlying the innovation is a public good. Second, that innovation is a private good with positive externalities. The third case concerns whether innovation is subject to uncertainty and large fixed costs, which, together with imperfect capital markets, can lead to underinvestment. The fourth example is whether competition to be the first to innovate creates duplication and excess costs.

\section{Case 1: Is New Knowledge a Public Good?}

The defining characteristic of a public good is that it is nonrival, which means that any single use of the public good does not affect its availability to other users. A nonrival good is one that can be used simultaneously by many people; its use by one person does not make it harder for other people to use the same nonrival good, nor does it reduce the value of the good to the first user when a second user is present. The typical textbook example is defense of the country, which provides a service for an entire population. An example of a nonrival knowledge good is a mathematical theorem.

A public good may also be nonexcludable: its use by one party still implies access for all, which cannot easily be blocked. In this case we call it a pure public good. Thus in the case of defense, it is not possible to exclude some members of society from enjoying its value. For our knowledge example, the key issue is how easily it can be accessed, as it does not simultaneously appear in the ether. Even in the days of paper and print, reproduction of a mathematical theorem was easy; with the arrival of the Internet the transmission of the theorem across the world is hard to suppress. An important example of these issues is the human genome project (HGP). A consortium of countries led by the United States started the HGP in 1990 with the aim of mapping the chemical composition of DNA. This publicly funded project was officially completed in 2003 and the knowledge is available on the Internet. Interestingly, a private firm, Celera, was started in 1998 to compete with the publicly funded HGP and it made thousands of patent applications in an attempt to claim intellectual property over the knowledge (i.e., make the knowledge excludable). However, various rulings by the United States Patent and Trademark Office (USPTO) and judgements by the courts have meant that very few patents have been granted. Celera ultimately donated its 
knowledge to the public domain in 2005 (see Angrist and Cook-Deegan 2006).

Once the nonrival public good has been provided, or discovered in the case of knowledge, the marginal cost of an extra user of such a good is zero. Economic theory tells us that resources are allocated efficiently when prices are equated to marginal costs. If a positive price is charged, then the price of a nonrival good is above zero, so there is a loss of efficiency, as some potential users may be excluded. If a zero price is all that is possible, then private firms motivated by the desire for profit will not produce or develop it. This was pointed out by Arrow (1962, p. 616): when discussing R\&D activity in firms, he concluded that

Any information obtained... should, from a welfare point of view, be available free of charge.... This ensures optimal utilization of the information, but of course provides no incentive for investment in research.

Geroski (1995, p. 91) agreed with the notion of innovation as a nonexcludable good:

The feature of inventive and innovative activity that most clearly sets it apart from other strategic investments made by firms is the problem of appropriability.

The problem of appropriability refers to the idea that the innovator cannot obtain the full value of its innovation from potential users. Perhaps we should consider whether there is a spectrum of types of new knowledge and innovation, not all of which conform to the "pure public good" definition.

Is every type of new knowledge nonrival? Consider the discovery of a new technology, based on biotechnology research, for designing drugs that have important curative properties. The use of the derived innovative process by one economic actor certainly does not preclude its use by another, but, unlike the pure mathematical theorem, the use by a second or third party will affect the market value of the discovery to the first producer. Even though the use by the imitator does not deplete the knowledge stock of the inventor, it certainly depletes his profits. So within the commercial world, the value of the new knowledge can be rival, even though the knowledge itself is intrinsically nonrival.

Is all knowledge nonexcludable? Clearly, in some cases its creator may be able to use IPRs to protect some of its value. But even without IPRs there is the possibility of using secrecy. If a food or drink supplier offers a new item for sale, he does not have to simultaneously reveal the recipe by which it was created. He can also write contracts with his employees 
to constrain them not to reveal the recipe. (This has been the approach taken by the producers of Coca Cola for many years.) Thus in many instances producers can prevent other producers from benefiting freely from the use of the new knowledge, when trade secrecy is a legitimate possibility as it is in many countries.

\section{Case 2: Are There Externalities from Innovative Activity?}

To continue our attempt to identify causes of market failure we can separate new knowledge from its application in a variety of innovations and then consider another useful economic model of commercial innovation: that of a private good with externalities. ${ }^{14}$ Production externalities arise when the profit-seeking activities of one firm create positive or negative effects for other firms and where these side effects are not priced and cannot be sold through the market. Positive externalities occur when the unpriced effects arising from one producer's activity improve the profits of other firms, as seen in our examples of new intermediate goods, or when the innovation improves the welfare of consumers more than the extent of any charge for the product decreases consumers' welfare, as happens when a better-quality final product is supplied for the same price. $^{15}$

It is useful to classify the different stages of R\&D, innovation, and diffusion illustrated in figure 1.1 into a spectrum of types of public and private goods. Basic research has more the nature of a public good because its applications can be in different fields (and diverse applications are nonrival). For example, recent research into how a spider creates and spins its silk is leading to applications in medicine for building human tissue and in cosmetics for better hair shampoo (as reported on The Material World, BBC Radio 4, November 9, 2006). Also, once a scientific discovery is made it is hard to suppress it or keep it secret, so basic scientific knowledge is also more likely to be nonexcludable. In contrast, when we get to the point of a particular application of knowledge, a firm undertaking near-market applied $R \& D$ and introducing a specific innovation is closer to supplying a private good with externalities.

\footnotetext{
${ }^{14}$ Negative externalities, such as pollution, tend to dominate discussions in microeconomics textbooks, but positive externalities from knowledge generation are equally important.

${ }^{15}$ Some economists refer to these as "pecuniary externalities," since they occur in relation to prices. There is also a link to the microeconomic concept of consumer surplus, which is generated when some consumers do not pay their full reservation price for the product they are buying. Given the possible confusion, it is wise to explain clearly what is meant when using these terms.
} 


\section{Case 3: Indivisibilities, Uncertainty, and Capital Markets}

Further insights concerning possible market failure come from other areas of economic theory, as much R\&D has the characteristic of indivisibility of investment and uncertainty of returns. Indivisibility refers to the idea that the project cannot be broken down into smaller, more manageable units. This indivisibility means that projects have up-front costs, known as "fixed costs." 16 If these are very large, they can act as a barrier to undertaking the project. Where there are large fixed costs in creating knowledge, but small marginal costs in supplying it once a discovery is made, this makes competitive market pricing unlikely, as it will not cover all the costs. A good example is the creation of new software: there are very large fixed costs in writing and perfecting the software code, while the production and distribution costs can be negligible. The low production and distribution costs, or marginal costs as economists call them, suggest that the software should have a low price (equal to marginal cost ideally). But such a low price will generate very little revenue and will not therefore compensate the creator for the fixed costs incurred.

Uncertainty is inherent in the innovation process, as decisions to bear risk by doing R\&D cannot be separated as an element of choice from decisions to wait for returns (investment), as noted by Arrow (1962). This is because insurance against the failure to discover something important and profitable by undertaking $R \& D$ is not on offer. This concentration of risk onto particular firms who decide to engage in R\&D may lead to underinvestment, especially in smaller firms, which cannot use product diversity to spread their R\&D risk within the firm. ${ }^{17}$

Both uncertainty and indivisibilities could be solved if capital markets worked perfectly. This refers to the idea that investors would correctly evaluate the expected value of any investment project (including R\&D projects) and would allocate funds to the projects with the highest returns. Uncertainty can be dealt with by investors diversifying their portfolios. However, there are reasons to expect problems in financing innovation. Banks, venture capitalists, and other investors attempt to find the best projects, but there can be difficulties in understanding and

\footnotetext{
${ }^{16}$ If these costs are unrecoverable, in that what they purchase has no resale value, they are known as "sunk costs."

${ }^{17}$ This argument is, in fact, more complex than it may seem. It is based on the assumption that entrepreneurs and firms are risk averse. If they are, in fact, risk takers, then this "market failure" may not occur. In addition, larger firms may be able to reduce uncertainty by carrying out a range of R\&D activities, again alleviating the market failure. Finally, one should be asking what is societal choice with regard to investment in uncertain projects and how does the market outcome compare to this.
} 
evaluating the project if it is related to innovation. Put simply, the innovator may be the only one who fully understands the project; hence the investor must trust the judgement of the innovator. Venture capitalists have considerable experience in evaluating innovative projects, but they themselves have fixed costs. For example, a full evaluation of a project may cost $\$ 40,000$; hence if the innovator is only seeking investment of $\$ 100,000$ this may preclude the venture capitalist becoming involved.

\section{Case 4: Patent Races and Duplication}

The final possibility for the existence of market failure concerns the fact that firms may compete head-to-head in the innovation process. So far we have implicitly assumed that each firm produces a different product or process innovation. However, it is possible that firms compete to make exactly the same innovation (e.g., finding a cure for a specific type of illness). In such situations there may be duplication of R\&D. However, since it is often not possible to foresee such cases, it is not easy to prevent such duplication. The economic literature has characterized this situation as a "patent race," with the implication being that the winner takes all of the returns. However, as we see in our later discussions, doing $\mathrm{R} \& \mathrm{D}$ in a common field is often necessary for firms that wish to engage in the exchange of information and technology and to benefit from others' advances. We return to these issues below in chapters 6 and 11 .

\section{Summing Up}

This discussion highlights the likelihood of various market failures occurring in the process of generating innovations. The first key insight comes from the appropriability problem for firms that invest in new knowledge. If a new discovery can be easily replicated, depleting the profits of the inventor, this creates a serious possibility of market failure resulting in underinvestment of resources in innovation.

The second key insight comes from the fact that many innovations require considerable amounts of $R \& D$ expenditure. Such investment is often highly uncertain and there are no insurance markets with which to offset these risks, so this may discourage optimal levels of investment. In addition, some investment projects may require very large fixed costs, hence even the largest firms may be discouraged without government support (e.g., nuclear power, or the creation of a new passenger aircraft). If capital markets worked perfectly, these issues may not cause problems, but this is unlikely to be the case. These arguments also suggest that investment in some types of innovation may be too low or nonexistent. 
The third key insight comes from thinking about the price of an innovation. Once an innovation has been made, its availability will be too low if there are private property rights over what should be a free public good, since the price will be set too high and this monopoly pricing inhibits diffusion. But if we always insist on immediate marginal cost pricing, there will be little incentive to invest. Thus Arrow (1962, pp. 61617) states that "in a free enterprise economy the profitability of invention requires a suboptimal allocation of resources." Some reward system or a degree of private ownership is needed for what may really be a public good if there is to be an incentive to produce it.

\subsection{Restoring Incentives to Invent and Innovate}

We can now explore some standard solutions provided in the literature for correcting market failure to see if these offer solutions in the case of R\&D and innovation. There are four main policy options for solving the problem of underprovision in the cases of public goods and private goods with positive externalities.

\section{Solution 1: Public Provision of a Public Good}

Government subsidy to basic research exists in many countries through the funding of university research and of special research agencies in fields such as defense and agriculture. This follows the idea that basic science is a public good. Funding is provided from general taxation and the results of the research are distributed freely without the need for the users of the knowledge to pay more than the marginal cost of its reproduction. This method of financing and provision is less suitable for nearmarket commercial research, where firms will have competing interests, but is more appropriate for the scientific end of basic research, where there are noncompeting uses in a variety of fields of application. Nevertheless, as we shall discuss below (chapter 4), many publicly funded institutions now engage in the privatization of ownership of their outputs through the use of IPRs and charging licensing fees above those of marginal reproduction costs.

\section{Solution 2: Club Provision of a Local Public Good}

A local, or impure, public good arises in the situation where a number of consumers value a service or facility that is nonrival up to a point, but congestion and rivalry then occurs. Provided that exclusion is possible, a 
club can be formed in which members all pay a fixed fee to join and thereafter pay a low marginal cost price to use the facility. An example would be a golf club that requires members to pay a large initial fee on joining followed by modest green fees when playing a round. As the club has a well-defined territory from which nonmembers can be excluded, those who join can be confident that their initial investment in membership awards them rights of access that cannot be eroded by nonmembers.

What relevance has this to innovation? This type of solution can occur where there is a need for specialized R\&D with the characteristics of high initial fixed costs together with low marginal costs in use. For the club to be feasible, there must be a possibility of exclusion, so that only those who contribute to the initial fixed costs are permitted to use the facility or information. This arrangement can come about where there are a limited number of players in a given product field, who can all benefit from investment in developing a new process or technique that could reduce their production costs and/or raise their product quality.

A research joint venture (RJV) represents an agreement to share the financing of R\&D between several firms, or between government and one or more private firms, together with an agreement for joint use of the scientific output. Provided that all the major potential users of the research output engage in the collaboration, this works to achieve a social optimum, as there are few problems of exclusion from the use of the discoveries, which might cause market distortion. ${ }^{18}$ These agreements are more likely to occur where the users of the invention do not compete too closely; an example is that Japanese firms are known to collaborate in basic research but not in near-market research, where the uses of innovation become more closely competitive (Goto 1997). In some cases where there are only two, or a small number of, firms, a merger between them will have the effect of removing the public good problem. This solution is also known as "internalizing the externality."

Our two remaining methods of solving the underprovision of innovation are derived from the economics of markets exhibiting externalities in production.

\section{Solution 3: Pigovian Subsidies}

The classic solution to externalities was proposed by Pigou (1932), who advocated the use of taxes or subsidies to correct negative or positive externalities respectively. In the case of innovation arising from

\footnotetext{
${ }^{18}$ As noted above (p. 19), resources are allocated efficiently when price equals marginal cost. If some large potential users remain outside of the RJV, so do not share the patents, they may be excluded by licensing fees that are above marginal cost.
} 


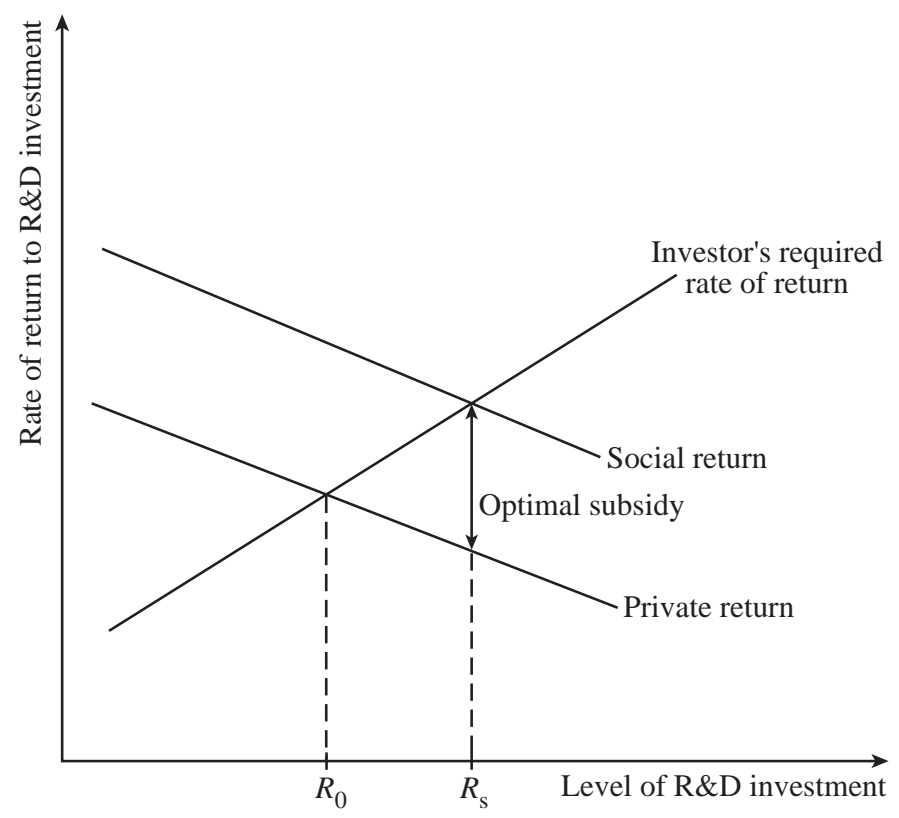

Figure 1.6. The role of $R \& D$ subsidies in correcting market failure.

Notes. Without any subsidy, private investors equate their expected private return to their required rate of return (the rate that covers the cost of investment funds) and the result is a level of investment of $R_{0}$. The socially optimal level of R\&D investment is where the social return is equated to the opportunity cost of funds. The social return is higher due to the positive externalities of R\&D. With a subsidy to R\&D the government effectively raises the private return to equal the social return and so private investors now choose the socially preferred higher level of investment $R_{\mathrm{S}}$.

production, this involves a subsidy to the activity that benefits other producers. In this way the innovator is rewarded at the social marginal cost and thus faces the correct incentive to produce innovative products and ideas. In the case of R\&D, the role of the subsidy is to raise the private rate of return to equal the social rate of return (see figure 1.6). Governments often finance basic research in universities and research institutes; however, there is not always a government subsidy for nearmarket research. Among the G5 countries, the United States, Japan, and France offer tax concessions to companies engaging in R\&D but Germany does not and the United Kingdom did not do so (except for small firms) until 2002.

Why might a government be unwilling to offer any subsidy to R\&D? One difficulty is in identifying which of the firm's expenses should be classified as constituting R\&D, which merit the tax concession or subsidy, as opposed to general production and marketing expenses, which do 
not. Another difficulty is that some R\&D is very successful while other projects are not. If all R\&D is subsidized at the same rate, regardless of how successful it is, then government is rewarding projects that are generating no positive externalities as well as those that are doing so. Just as problematic is the fact that much R\&D would still be done in the absence of any R\&D subsidy. In this case the government contribution represents a gift to those companies that are persistently active in R\&D. We shall discuss these issues further in chapter 11, where we examine a number of policy instruments to promote innovation.

\section{Solution 4: Definition of Property Rights}

The insight of Coase (1960) was that, in dealing with externalities, any unpriced spillover (an externality) could be brought within the market system (or internalized) if a property right can be assigned over the externality (whether good or bad). Once property rights are assigned, contracts can be written and the market can then function. Those who create positive externalities can charge others for these benefits, while those who create negative externalities, such as pollution, can be charged by the recipients. In regard to innovation activity, the parallel is that, if intellectual property rights can be defined (and defended in law) and a system of private bargaining and contracting for the use of the invention or information can be established, then the market may be able to move closer to achieving the socially optimal level of innovation. The requirements for this to work are divisible, measurable externalities; small numbers of affected parties who can then engage in contracts; full information for those affected about the values of the intellectual property assets; and the rights to license the intellectual property.

Patents, copyright, trademarks, and design protection systems can be viewed as coming in this orbit (albeit they predate the Coase theorem). Two important caveats arise in interpreting IPRs in this way. The first concerns Coase's symmetry result for common externalities such as pollution: it makes no difference to the achievement of a socially efficient outcome whether the right to pollute is assigned to the polluter or the polluted. In this example the pollution occurs as a byproduct of another activity that is the main motivation of the producer. This result does not carry over to IPRs, where we are considering the right to ownership of the whole of the benefits flowing from an innovation that has yet to be discovered. The innovator requires future property rights to provide an incentive. If all the returns were preassigned to the future beneficiaries, they are unlikely to be willing or able to combine to offer him a fee to invent, particularly given the uncertainty of the R\&D process and the 
users' difficulty in valuing something that does not yet exist. However, some stages of an ongoing R\&D process can be subcontracted, with contracts being drawn up at the outset, detailing the ownership of future IPRs and the allocation of the rewards from licensing technology.

The second caveat regarding IPRs as Coasian property rights is the issue of how far knowledge is a nonrival public good rather than a rival private good, as we discussed above. Nonrival goods can sometimes be made excludable: a good is said to be excludable if it is possible to prevent its use by others. Acquiring an IPR for a particular creation of knowledge may be an example of making a nonrival good excludable. ${ }^{19}$ Economists are particularly interested in this feature of IPRs. Economists and others have long argued that strong property rights applied to rival goods result in efficient outcomes. In contrast, strong property rights for nonrival goods involve a trade-off.

\section{The Trade-off between Incentives and Monopoly Power}

To give people an incentive to produce socially desirable new innovations, IPRs allow the creators of a nonrival good to appropriate the returns of their innovation for themselves. But since IPRs make a nonrival good excludable, this gives rise to inefficiency, since the price of the good will be above the marginal cost of producing it. In other words, granting an IPR to an entity is tantamount to conferring a monopoly. The knife-edge on which the intellectual property law tries to balance is that of defining enough private property rights to preserve adequate incentives for innovation while avoiding the gift of excessive monopoly power, which will lead to socially inefficient exploitation of that creation. Economists are then left to adjudicate as to the desirability of using IPRs, given that they act as a spur to innovation and also as an instigator of monopolistic inefficiency.

This trade-off between encouraging innovation and suffering the consequences of monopoly has been noted by many writers and was formally analyzed in a modern way by Nordhaus (1969). We shall explore these issues of monopoly gains and distortions more fully in chapter 2 . In addition, understanding whether these monopoly costs of IPRs are less than the benefit to society emanating from the spur that IPRs give to innovation will provide a major theme for parts II and IV of this book.

\footnotetext{
${ }^{19}$ However, the boundaries of any IPR are "fuzzy" due to the difficulties of complete enforcement and the possibility that competitors learn from the documentation of the innovation.
} 


\subsection{Firms Competing through Innovation}

Up to now our discussion has focused on the nature of innovation and the incentives faced by individual firms without much consideration of the interactions between firms in the marketplace. One of the first authors to discuss this interaction was Schumpeter (1942), who coined the now-famous term "creative destruction" to describe the outcome of the process of innovation by competing firms interacting in a given marketplace. This was a perceptive appreciation of the tension between the benefits from innovation and the costs to other firms that are standing still in terms of product design and technology. Thus the term "creative" refers to the profitable opportunities seized by innovators, which ultimately benefit not just them but the whole society. The word "destruction" refers to the process whereby the innovator is taking away customers, and therefore profit, from existing producers. In this situation of competition for market share through the introduction of novel products and processes, there is likely to be a continual churning of market leadership. Pervasive uncertainty about any firm's continued existence is the norm if it fails to innovate or to catch up quickly with the leaders through imitation.

This description of the interaction between firms points out a basic incompatibility between perfect competition (in the absence of IPRs) and modern entrepreneurial activity, because immediate imitation reduces the incentives to innovate to zero. Perfect competition may then be inferior to another more concentrated market structure that is more conducive to innovation, particularly in markets where IPRs cannot easily be assigned. ${ }^{20}$ In his later writings Schumpeter championed oligopoly, seeing this as a market structure whose competitive practices of intensive competition between a few large firms, creating new products and lowering costs, achieved more for social welfare than either perfect competition or monopoly. However, the debate about the merits of large and small firms as innovators and the optimal degree of market concentration has continued in the literature to this day. We shall return to this topic in chapter 5 .

It should be clear from the discussion above that IPRs are central to the process of innovation. The basic argument is that IPRs award temporary monopoly rights, something society does not want, in order to provide incentives to innovate, something society does want. However, in reality the IPR system creates a complex set of decisions for firms.

\footnotetext{
${ }^{20}$ In most mixed-market economies today, the antitrust or competition policy authorities are charged with taking innovation into account when enforcing antimonopoly laws.
} 
Chapter 6 discusses in detail how firms can benefit from the IPR system, including a discussion on when the IPR system may be detrimental to certain firms. Following this, in chapter 7, we examine how innovations spread across the economy, so that ultimately the innovative product or process becomes the new standard for consumers or producers. At the point where the process of diffusion is complete, society is reaping the full benefit of the new knowledge.

\subsection{Conclusion}

This chapter has provided an introduction and overview of the nature of innovation. There should be little doubt that innovation is a complex process-even defining innovation is problematic! The genesis of innovation derives from a wide range of sources and its development involves various stages, often involving considerable investment. Although we can outline the stages of innovation (figure 1.1), progression through them is not linear and there are important feedbacks in the process. While entrepreneurs and private firms are central actors in the process, there is a critical role for government in providing a legal infrastructure and supplying basic scientific knowledge. Many aspects of the process are subject to market failures and the existence of the IPR system is one attempt to remedy some of these. All of these issues are returned to in part II of the book. In the rest of part I we continue with our microeconomic analysis by considering the role of IPRs in chapter 2 and the thorny issue of how we can observe and measure innovation and productivity in chapter 3 .

\section{Keywords}

Invention, innovation, and diffusion.

Product and process innovation.

Intellectual property rights.

Market failure.

Public goods.

Externality.

Appropriability.

Coasian property rights.

Pigovian subsidies.

Creative destruction. 
1. The Nature and Importance of Innovation

\section{Questions for Discussion}

(1) How would you distinguish between an invention and an innovation?

(2) What are the key characteristics of a public good? Is all new knowledge a public good?

(3) What is a positive externality? How does this differ from a public good?

(4) How does innovation create positive externalities? Why are they a problem?

(5) What are the key market failures surrounding investment in innovation?

(6) Does the creation of intellectual property rights help or hinder the markets for innovative goods and processes?

\section{References}

Angrist, M., and R. Cook-Deegan. 2006. Who owns the genome? The New Atlantis: A Journal of Technology and Society Winter:87-96.

Arrow, K. 1962. Economic welfare and the allocation of resources for invention. In The Rate and Direction of Inventive Activity (ed. R. Nelson). National Bureau of Economic Research/Princeton University Press.

Coase, R. 1960. The problem of social cost. Journal of Law and Economics 3: $1-44$.

Geroski, P. 1995. Markets for technology: knowledge, innovation and appropriability. In Handbook of the Economics of Innovation and Technical Change (ed. P. Stoneman), chapter 4. Oxford: Basil Blackwell.

Goto, A. 1997. Co-operative research in Japanese manufacturing industries. In Innovation in Japan (ed. A. Goto and H. Odagiri). Oxford: Clarendon.

Greenhalgh, C. A., and M. Rogers. 2006. The value of innovation: the interaction of competition, R\&D and IP. Research Policy 35:562-80.

Leontief, W. 1986. Input-Output Economics, 2nd edn. Oxford University Press.

Nordhaus, W. 1969. Invention, Growth and Welfare: A Theoretical Treatment of Technological Change. Cambridge, MA: MIT Press.

OECD. 1997. The Oslo Manual: Proposed Guidelines for Collecting and Interpreting Technological Innovation Data. Paris: Organisation for Economic Cooperation and Development.

Pavitt, K. 1984. Sectoral patterns of technical change. Research Policy 13:343-73. Pigou, A. C. 1932. The Economics of Welfare, 4th edn. London: Macmillan.

Rosegger, G. 1986. The Economics of Production and Innovation, 2nd edn. Oxford: Pergamon Press.

Rosenberg, N. 1982. Inside the Black Box. Cambridge University Press.

Scherer, F. M. 1984. Innovation and Growth: Schumpeterian Perspectives. Cambridge, MA: MIT Press. 
Schumpeter, J. A. 1942. Capitalism, Socialism and Democracy, reissued 1975. New York: Harper \& Row.

Tidd, J., J. Bessant, and K. Pavitt. 2001. Managing Innovation: Integrating Technological, Market and Organisational Change. John Wiley.

von Hippel, E. 2005. Democratizing Innovation. Cambridge, MA: MIT Press. 